\title{
Formulation and evaluation of microspheres containing ropinirole hydrochloride using biodegradable polymers
}

\author{
Jyotsana R. Madan, Vinod Kadam¹, Sudarshan Bandavane ${ }^{1}$, Kamal Dua ${ }^{2}$ \\ Departments of Pharmaceutics, and ${ }^{1}$ Smt. Kashibai Navale College of Pharmacy, Pune, Maharashtra, India, ${ }^{2}$ School of Pharmacy, \\ International Medical University, Bukit Jalil, 57000 Kuala Lumpur, Malaysia
}

\begin{abstract}
$T$ The present work relates with developing long acting sustain release microspheres of ropinirole hydrochloride (RPN) for treatment of Parkinson's disease, that will sustain drug release up to 1 month. Biodegradable microspheres of RPN were prepared by using two different polymers (poly lactic co glycolic acid [PLGA] 50:50 and PLGA 75:25) employing double emulsion $(\mathrm{W} / \mathrm{O} / \mathrm{W})$ solvent evaporation method. Preliminary optimization of process parameter was done for concentration of polyvinyl alcohol (PVA) solution, stirring speed, temperature of PVA solution, ratio of the drug to polymer (D/P) and ratio of internal phase to external phase volume (IP/EP). All formulations were evaluated for particle size, percentage yield, entrapment efficiency (EE), shape etc. Formulation E3 and E4 shows maximum EE. \% in vitro drug release per day of E3 and E4 batch was studied. The RPN was incorporated successfully in microspheres prepared with $0.5 \% \mathrm{w} / \mathrm{v}$ PVA at $8000 \mathrm{RPM}$ stirring speed, $20^{\circ} \mathrm{C}$ processing temperature, 1:4 drug polymer ratio and 1:30 IP/EP ratio, which provides sustained release up to 4 weeks with better efficacy and patient compliance and can be employed as an alternative to existing oral medications.
\end{abstract}

Key words: Entrapment efficiency, poly lactic co glycolic acid 50:50, polyvinyl alcohol, solvent evaporation, sustained release

\section{INTRODUCTION}

Parkinson's disease is a chronic disorder for which lifelong treatment with antiparkinsons drugs is necessary. Antiparkinsons drugs are not readily accepted by patients, thus, non-compliance is common. ${ }^{[1,2]}$ Microspheres made up of biodegradable polymers, can be injected with a syringe into the body and once injected, solidify to form a semi-solid depot. ${ }^{[3,4]}$ They are considered as a useful therapeutic option in patients with parkinsonism who lack insight or are known to adhere poorly to oral medications. Long-acting injectable antiparkinsons drugs have demonstrated a number of advantages over oral medication, including stabilization of serum drug levels, avoidance of the first pass metabolism, assured medication delivery and well-controlled titration to lowest effective doses.

Long-acting injectables reduce variation between peak and trough levels and have lower peak concentrations

Address for correspondence: Dr. Jyotsana R. Madan,

Department of Pharmaceutics, Smt. Kashibai Navale College of Pharmacy, Pune - 411 048, Maharashtra, India. E-mail: jyotsna.madan@sinhgad.edu that can reduce the incidence of adverse effects. ${ }^{[5,6]}$ Depot formulations have been well tolerated and more efficacious than their oral equivalents. In view of the need to provide extended release of antiparkinson drugs for longer duration with better patient compliance, the present study has been directed toward the incorporation of antiparkinson drug, ropinirole hydrochloride (RPN) into polymeric biodegradable microspheres formulation.

\section{MATERIALS AND METHODS}

RPN was obtained as a gift sample from Hetero Drugs Pvt. Ltd., Hyderabad, India. Poly lactic co glycolic acid (PLGA) 50:50 (PUROSORB 5002 PDLG) was generously provided by PURAC Biopolymers, Netherland. PLGA 75:25 (RESOMER 752S) was gifted by Evonik Polymers, Mumbai. Dichloromethane (DCM) and

\begin{tabular}{|l|l|}
\hline \multicolumn{2}{|c|}{ Access this article online } \\
\hline Quick Response Code: & Website: \\
& \\
\end{tabular}


polyvinyl alcohol (PVA) were gifted by Loba Chemical Pvt. Ltd, Mumbai. All other chemicals used were of analytical grade.

RPN microsphere preparation using double emulsion solvent evaporation technique

RPN was dissolved in 1-2 ml distilled water. It was sonicated (Oscar Ultrasonics, Mumbai) for $3 \mathrm{~min}$. with organic phase containing $5 \mathrm{ml}$ of DCM and PLGA polymer (300 mg, $400 \mathrm{mg}, 500 \mathrm{mg})$ for $10 \mathrm{~min}$, which forms (W/O) primary emulsion. The obtained primary emulsion $(6 \mathrm{ml})$ was further emulsified with aqueous PVA solution $(0.5,1$ and $2 \% \mathrm{w} / \mathrm{v}$ at different volumes viz. $300 \mathrm{ml}, 180 \mathrm{ml}, 120 \mathrm{ml}$ ) using high speed homogenizer (REMI, India) at varying speed (6000, $8000,10,000 \mathrm{rpm})$, which forms W/O/W secondary emulsion. The resultant solution was stirred for $4 \mathrm{~h}$ to evaporate the solvent completely. Further, the microspheres were washed with distilled water, filtered by vacuum filtration and kept in vacuum desiccators for $12 \mathrm{~h}$. Dried microspheres were collected in well-labeled glass vials and stored at $2-8^{\circ} \mathrm{C}$ temperature.

In order to optimize the formula of the microspheres, the following process and formulation variable parameters were studied; PVA concentration, stirring speed of homogenizer, process temperature of PVA solution, drug: polymer ratio (D/P ratio) and ratio of internal phase/external phase volume (IP/ EP ratio).

Optimization of process parameters

PLGA loaded RPN microspheres were prepared by using double emulsion solvent evaporation by changing the concentration of EP of the secondary emulsion (PVA solution) as shown in Table 1. Based on the results obtained, concentration of PVA solution was fixed to $0.5 \% \mathrm{w} / \mathrm{v}$ and kept constant for further B1 to B6 batches. Further RPN microspheres batches were prepared by varying stirring speed (6000-10000 rpm) using high speed homogenizer (REMI, India) as shown in Table 2.

Batches $\mathrm{C} 1$ to $\mathrm{C} 6$ were prepared by fixing stirring speed to $8000 \mathrm{rpm}$ to optimize temperature of EP (PVA solution) as shown in Table 3. Batches D1 to D6 were prepared by fixing temperature of PVA solution at $20^{\circ} \mathrm{C}$ to optimize drug/ polymer $(\mathrm{D} / \mathrm{P})$ ratio as shown in Table 4 .

Batches E1 to E6 were prepared by keeping PVA concentration $0.5 \%$ and stirring speed $8000 \mathrm{rpm}$, temperature of PVA solution $20^{\circ} \mathrm{C}$ and D/P ratio $1: 4$ to optimize IP (primary emulsion): EP volume of secondary emulsion ratio as shown in Table 5.

Table 1: Selection of PVA concentration

\begin{tabular}{|c|c|c|c|c|c|c|c|c|}
\hline $\begin{array}{l}\text { Formulation } \\
\text { code }\end{array}$ & Drug (mg) & $\begin{array}{c}\text { PLGA } \\
50: 50(\mathrm{mg})\end{array}$ & $\begin{array}{c}\text { PLGA } \\
\text { 75:25 (mg) }\end{array}$ & $\begin{array}{c}\text { PVA } \\
\text { concentration (\%) }\end{array}$ & $\begin{array}{c}\text { Mean particle } \\
\text { size }(\mu \mathrm{m})\end{array}$ & EE & Yield (\%) & Shape \\
\hline A1 & 100 & 300 & & 0.5 & 25 & 44.3 & 75.3 & Spherical \\
\hline $\mathrm{A} 2$ & 100 & & 300 & 0.5 & 30 & 46.7 & 78.5 & Spherical \\
\hline A3 & 100 & 300 & & 1 & 18 & 30.4 & 72.8 & Spherical \\
\hline A4 & 100 & & 300 & 1 & 21 & 32.4 & 70.2 & Spherical \\
\hline A5 & 100 & 300 & & 2 & 12 & 25.8 & 68.9 & Irregular \\
\hline A6 & 100 & & 300 & 2 & 16 & 27.2 & 68.4 & Irregular \\
\hline
\end{tabular}

PVA: Polyvinyl alcohol, PLGA: Poly lactic co glycolic acid, EE: Entrapment efficiency

Table 2: Selection of stirring speed

\begin{tabular}{|c|c|c|c|c|c|c|c|c|}
\hline $\begin{array}{l}\text { Formulation } \\
\text { code }\end{array}$ & Drug (mg) & $\begin{array}{c}\text { PLGA } \\
50: 50(\mathrm{mg})\end{array}$ & $\begin{array}{c}\text { PLGA } \\
75: 25(\mathrm{mg})\end{array}$ & $\begin{array}{c}\text { Stirring } \\
\text { speed (rpm) }\end{array}$ & $\begin{array}{l}\text { Mean particle } \\
\text { size }(\mu \mathrm{m})\end{array}$ & EE (\%) & Yield (\%) & Shape \\
\hline $\mathrm{B} 1$ & 100 & 300 & & 6000 & 33.4 & 47.2 & 68.8 & Spherical \\
\hline B2 & 100 & & 300 & 6000 & 27.8 & 48.2 & 68.5 & Spherical \\
\hline B3 & 100 & 300 & & 8000 & 17.8 & 50.5 & 76.8 & Spherical \\
\hline B4 & 100 & & 300 & 8000 & 17.6 & 49.6 & 76.5 & Spherical \\
\hline B5 & 100 & 300 & & 10000 & 10.9 & 26.2 & 66.7 & Irregular \\
\hline
\end{tabular}

PLGA: Poly lactic co glycolic acid, EE: Entrapment efficiency

Table 3: Selection of PVA temperature

\begin{tabular}{|c|c|c|c|c|c|c|c|c|}
\hline $\begin{array}{l}\text { Formulation } \\
\text { code }\end{array}$ & Drug (mg) & $\begin{array}{c}\text { PLGA } \\
50: 50(\mathrm{mg})\end{array}$ & $\begin{array}{c}\text { PLGA } \\
75: 25(\mathrm{mg})\end{array}$ & $\begin{array}{c}\text { Temperature of } \\
\text { PVA solution }\left({ }^{\circ} \mathrm{C}\right)\end{array}$ & $\begin{array}{c}\text { Mean particle } \\
\text { size }(\mu \mathrm{m})\end{array}$ & EE (\%) & Yield (\%) & Shape \\
\hline $\mathrm{C} 1$ & 100 & 300 & & 15 & 31.4 & 31.2 & 70.2 & Irregular \\
\hline $\mathrm{C} 2$ & 100 & & 300 & 15 & 30.8 & 32.3 & 76.2 & Irregular \\
\hline C3 & 100 & 300 & & 20 & 22.1 & 40.3 & 76.3 & Spherical \\
\hline $\mathrm{C} 4$ & 100 & & 300 & 20 & 20.4 & 41.5 & 77.7 & Spherical \\
\hline C5 & 100 & 300 & & 30 & 16.8 & 36.4 & 70.2 & Irregular \\
\hline C6 & 100 & & 300 & 30 & 17.2 & 36.9 & 70.4 & Irregular \\
\hline
\end{tabular}

PVA: Polyvinyl alcohol, PLGA: Poly lactic co glycolic acid, EE: Entrapment efficiency 
Madan, et al:: Microspheres containing ropinirole hydrochloride

Table 4: Selection of drug polymer ratio

\begin{tabular}{lcccccccc}
\hline $\begin{array}{l}\text { Formulation } \\
\text { code }\end{array}$ & Drug $(\mathbf{m g})$ & $\begin{array}{c}\text { PLGA } \\
\mathbf{5 0 : 5 0}(\mathbf{m g})\end{array}$ & $\begin{array}{c}\text { PLGA } \\
\mathbf{7 5 : 2 5}(\mathbf{m g})\end{array}$ & D/P ratio & $\begin{array}{c}\text { Mean particle } \\
\text { size }(\boldsymbol{\mu m})\end{array}$ & EE (\%) & Yield $(\%)$ & Shape \\
\hline D1 & 100 & 500 & & $1: 5$ & 26.38 & 56.7 & 72.4 & Spherical \\
D2 & 100 & & 500 & $1: 5$ & 27.2 & 56.8 & 72.6 & Spherical \\
D3 & 100 & 400 & & $1: 4$ & 16.8 & 48.5 & 78.3 & Spherical \\
D4 & 100 & & 400 & $1: 4$ & 16.7 & 47.3 & 79.4 & Spherical \\
D5 & 100 & \multirow{2}{*}{300} & & $1: 3$ & 10.3 & 30.8 & 74.6 & Irregular \\
D6 & 100 & & 300 & $1: 3$ & 9.5 & 27.8 & 73.7 & Irregular \\
\hline
\end{tabular}

PLGA: Poly lactic co glycolic acid, EE: Entrapment efficiency, D/P: Drug/polymer

Table 5: Selection of ratio of internal phase volume to external phase volume

\begin{tabular}{lcccccccc}
\hline $\begin{array}{l}\text { Formulation } \\
\text { code }\end{array}$ & Drug $(\mathbf{m g})$ & $\begin{array}{c}\text { PLGA } \\
\mathbf{5 0 : 5 0}(\mathbf{m g})\end{array}$ & $\begin{array}{c}\text { PLGA } \\
\mathbf{7 5 : 2 5}(\mathbf{m g})\end{array}$ & $\begin{array}{c}\text { IP/EP ratio } \\
\text { E1 }\end{array}$ & $\begin{array}{c}\text { Mean particle } \\
\text { size }(\boldsymbol{\mu m})\end{array}$ & EE (\%) & Yield (\%) & Shape \\
E2 & 100 & 400 & & $1: 50$ & 16.7 & 41.4 & 76.7 & Spherical \\
E3 & 100 & & 400 & $1: 50$ & 16.2 & 40.8 & 76.2 & Spherical \\
E4 & 100 & 400 & & $1: 30$ & 20.4 & 52.5 & 80.8 & Spherical \\
E5 & 100 & & 400 & $1: 30$ & 23.6 & 51.8 & 81.2 & Spherical \\
E6 & 100 & 400 & & $1: 20$ & 26.3 & 56.5 & 78.2 & Spherical \\
\hline
\end{tabular}

PLGA: Poly lactic co glycolic acid, EE: Entrapment efficiency, IP/EP: Internal phase/external phase

\section{EVALUATION OF MICROSPHERES}

Percent yield

Microspheres recovered at the end of preparation were weighed and the \% yield was calculated by using the following equation.

$\%$ Yield $=\frac{\text { Practical yield }}{\text { Theoretical yield }} \times 100$

Entrapment efficiency

To calculate the entrapment efficiency \% (EE), $10 \mathrm{mg}$ prepared microspheres were dissolved in $2 \mathrm{ml} \mathrm{DCM}$. Diluted up to $10 \mathrm{ml}$ with distilled water. This solution was subjected to centrifugation at $1000 \mathrm{rpm}$. Supernatant was filtered through $0.45 \mu \mathrm{m}$ filter. The absorbances of these solution was noted using ultraviolet (UV) spectrophotometric method at $\lambda$ max $249 \mathrm{~nm}$ and the \%EE was calculated using the following equation

$\%$ Entrapment efficiency $=\frac{\text { Amount of entrapped drug }}{\text { Amount of total drug used }} \times 100$

Particle size

The mean particle size of freshly prepared microsphere samples of each batch was determined by laser light scattering (model Mastersizer 2000, Malvern Instruments, Malvern, UK).

Surface morphology

Surface Morphology of E3 batch was studied by using scanning electron microscope (SEM) (Model: JEOLJSM-6360) with an accelerating voltage of $10 \mathrm{kV}$.

In vitro $\mathrm{RPN}$ release from microspheres

The in vitro drug release for batch E3 and E4 was performed in phosphate buffer, $\mathrm{pH} 7.4$ release media under sink conditions on shaker incubator (Chromous Biotech.) at a constant temperature $\left(37^{\circ} \mathrm{C}\right)$. Microspheres equivalent to RPN $56 \mathrm{mg}$ were dispersed in $5 \mathrm{ml}$ distilled water in dialysis bag, which is suspended in the volumetric flask containing $50 \mathrm{ml}$ of release media and kept for shaking in shaker incubator. At the set points, $3 \mathrm{ml}$ sample was removed by syringe for analysis through $0.45 \mu \mathrm{m}$ mdi nylon filters for which the concentration was analyzed at $249 \mathrm{~nm}$ by UV spectrophotometer. ${ }^{[7-9]}$

\section{RESULTS AND DISCUSSION}

The most suitable method for encapsulation of hydrophilic drugs into PLGA microspheres is the double emulsification solvent evaporation technique. ${ }^{[10]}$ The drug RPN, being water soluble, the double emulsification solvent evaporation method was selected. ${ }^{[11]}$ Multiple studies demonstrate that PLGA can easily be formulated into the drug carrying devices as microspheres. ${ }^{[12-15]}$

Table 1 shows that the particle size of RPN loaded PLGA microspheres were inversely proportional to the concentration of PVA solution used as EP. Previous investigations suggests that increasing the PVA concentration in the continuous medium reduces the particle size of microspheres. ${ }^{[16,17]}$ Increasing the PVA concentration leads to more PVA molecules overlaying the surface of the droplets and provided protection to the droplets against coalescence, which resulted in the production of smaller emulsion droplets $(25-30 \mu \mathrm{m})$.

Further, highest \% yield and \%EE of $78.5 \%$ and $46.7 \%$ respectively was obtained for $\mathrm{A} 2$ batch prepared using PVA solution at $0.5 \%$ concentration. Thus for further batches $0.5 \% \mathrm{~W} / \mathrm{v}$ PVA solution as aqueous phase was fixed. 


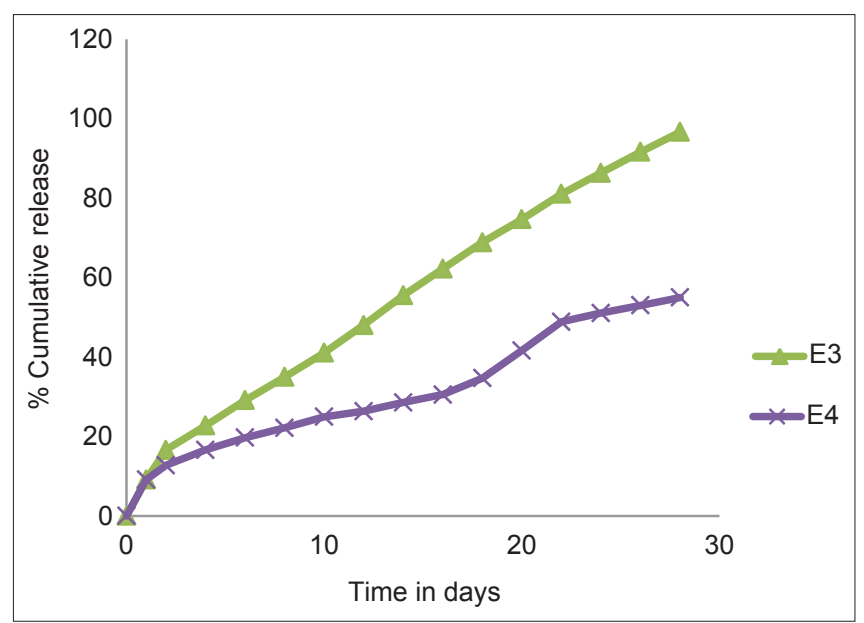

Figure 1: In vitro dissolution profile of formulation E3 and E4

Table 2 indicates that an increase in stirring speed from $6000 \mathrm{rpm}$ to $10000 \mathrm{rpm}$ decreases the microsphere size significantly from $33.4 \mu \mathrm{m}$ to $10.9 \mu \mathrm{m}$, but the \%EE was reduced to $26.2 \%$. The speed was therefore fixed to an optimum level of $8000 \mathrm{rpm}$ for further batches.

At a higher temperature of PVA solution $\left(30^{\circ} \mathrm{C}\right)$, it was observed that particle size was $17.2 \mu \mathrm{m}$ and at $15^{\circ} \mathrm{C}$ of PVA solution particle size of microspheres was observed to be $31.4 \mu \mathrm{m}$ to. This is due to the fact that the $\mathrm{W} / \mathrm{O} / \mathrm{W}$ double emulsion at high temperatures is less viscous, thus it is much easier for the emulsion to be broken up into smaller droplets at the same input power of mixing. ${ }^{[18]}$

The EE was decreased at both higher temperature of external aqueous phase $\left(30^{\circ} \mathrm{C}\right)$ and lower temperature $\left(15^{\circ} \mathrm{C}\right)$ as compared to $20^{\circ} \mathrm{C}$ where EE of about $41 \%$ was observed. For further batches $20^{\circ} \mathrm{C}$ temperature of PVA solution was fixed. It was observed [Table 4] that EE was decreased from $56.6 \%$ to $27.8 \%$ by changing $\mathrm{D} / \mathrm{P}$ ratio from $1: 5$ to $1: 3$. The $\mathrm{D} / \mathrm{P}$ ratio was fixed to 1:4 for further batches as at this ratio best $\mathrm{EE} \%(78-79 \%)$ was achieved. Table 5 reveals that $\mathrm{EE}$ and particle size decreases as the ratio of IP to EP was increased from 1:20 to 1:50. An increase in the volume of the EP of the secondary emulsion led to a decrease in the particle size of microspheres. The droplet size of the secondary emulsion may decrease because of a decrease in the frequency of collision of droplets with an increase in the volume of the EP of the secondary emulsion. ${ }^{[16]}$

IP to EP was further fixed to 1:30 to produce optimum particle size and to achieve a better entrapment (52\%). These optimized batches E3 and E4 were evaluated for percentage in vitro drug release by using dialysis bag method. Drug released through E3 formulation containing PLGA 50:50 is $96 \%$ at the end of 28 days and more uniform than E4 formulation containing PLGA 75:25, where only $52 \%$ drug was released at the end of 28 days as shown in Figure 1. Polymer composition is the most important factor to determine the hydrophilicity and rate of degradation of a delivery matrix. A systematic study of the polymer composition

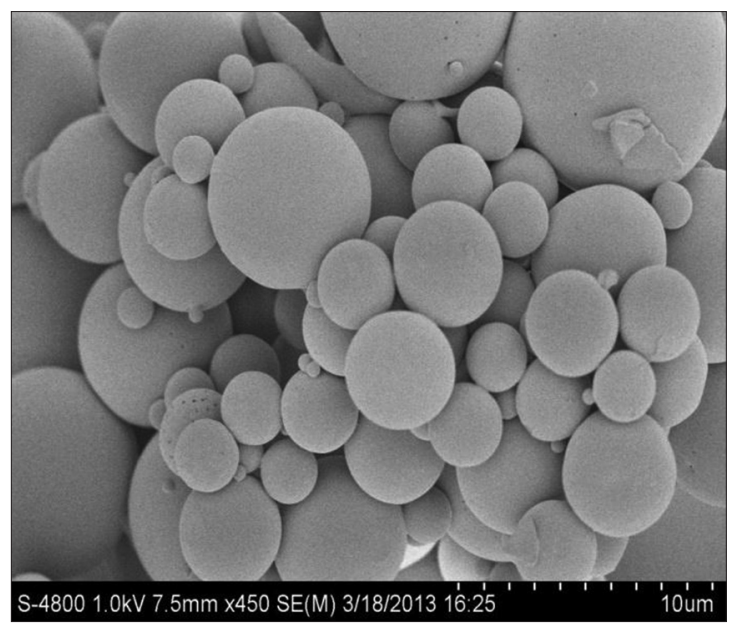

Figure 2: Scanning electron microscope microgarphs of microspheres

with its degradation has been shown by many groups..$^{19,20]}$

PLGA 50:50 (PLA/PGA) exhibited a faster degradation than PLGA 75:25 due to preferential degradation of glycolic acid proportion assigned by higher hydrophilicity. ${ }^{[20,21]}$ SEM micrographs of E3 formulation shows that PLGA 50:50 microspheres containing RPN are spherical in shape, having a smooth surface and size ranges from 20 to $25 \mu \mathrm{m}$ as shown in Figure 2.

\section{CONCLUSION}

For a short-term release requirement (up to 1 month), an amorphous polymer PLGA 50:50 is recommended. For a longer-term release requirement (1-6 months), the choice of an amorphous polymer PLGA 75:25 would be appropriate. From this study is concluded that the RPN can be incorporated successfully in microspheres prepared with $0.5 \% \mathrm{w} / \mathrm{v}$ PVA at $8000 \mathrm{RPM}$ stirring speed, $20^{\circ} \mathrm{C}$ processing temperature, 1:4 drug polymer ratio and 1:30 IP/EP ratio, which provides sustained release up to 4 weeks with better efficacy and patient compliance and can be employed as an alternative to existing oral medications.

\section{ACKNOWLEDGMENT}

The authors are thankful to Hetero Drugs Pvt. Ltd. (Hyderabad, India) for supply of gift sample of Ropinirole hydrochloride and the Management of Smt. Kashibai Navale College of Pharmacy, Kondhwa, Pune for providing necessary facilities to carry out this research work.

This research work has been funded by Board of College and University Development, University of Pune.

\section{REFERENCES}

1. Chaudhuri RK, Martinez-Martin P, Rolfe KA, Cooper J, Rockett CB, Giorgi L. Improvements in nocturnal symptoms with ropinirole prolonged release in patients with advanced Parkinson's disease. Eur J Neurol 2012;19:105-13.

2. Eden RJ, Costall B, Domeney AM, Gerrard PA, Harvey CA, Kelly ME, et al. 
Preclinical pharmacology of ropinirole (SK and F 101468-A) a novel dopamine D2 agonist. Pharmacol Biochem Behav 1991;38:147-54.

3. Hatefi A, Amsden B. Biodegradable injectable in situ forming drug delivery systems. J Control Release 2002;80:9-28.

4. Berkland C, Kim K, Pack DW. Fabrication of PLG microspheres with precisely controlled and monodisperse size distributions. J Control Release 2001;73:59-74.

5. Jain RA, Rhodes CT, Railkar AM, Malick AW, Shah NH. Controlled release of drugs from injectable in situ formed biodegradable PLGA microspheres: Effect of various formulation variables. Eur J Pharm Biopharm 2000;50:257-62.

6. Sun Y, Wang J, Zhang X, Zhang Z, Zheng Y, Chen D, et al. Synchronic release of two hormonal contraceptives for about one month from the PLGA microspheres: In vitro and in vivo studies.J Control Release 2008;129:192-9.

7. Jeffery H, Davis SS, O'Hagan DT. The preparation and characterization of poly (lactide-co-glycolide) microparticles. II. The entrapment of a model protein using a (water-in-oil)-in-water emulsion solvent evaporation technique. Pharm Res 1993;10:362-8.

8. Jiang W, Gupta RK, Deshpande MC, Schwendeman SP. Biodegradable poly (lactic-co-glycolic acid) microparticles for injectable delivery of vaccine antigens. Adv Drug Deliv Rev 2005;57:391-410.

9. Gu H, Song C, Long D, Mei L, Sun H. Controlled release of recombinant human nerve growth factor (rhNGF) from poly[(lactic acid)-co-(glycolic acid)] microspheres for the treatment of neurodegenerative disorders. Polym Int 2007;56:1272-80.

10. Conway BR, Oya AH. Double emulsion microencapsulation of proteins as model antigens using polylactide polymers: effect of emulsifiers on microsphere characteristics and release kinetics. EurJ Pharm Biopharm 1996;42:42-8.

11. Ogawa Y, Yamamoto M, Okada H, Yashiki T, Shimamoto T. A new technique to efficiently entrap leuprolide acetate into microcapsules of polylactic acid or copoly (lactic/glycolic) acid. Chem Pharm Bull (Tokyo) 1988;36:1095-103.

12. Aubert-Pouëssel A, Venier-Julienne MC, Clavreul A, Sergent M, Jollivet C, Montero-Menei $\mathrm{CN}$, et al. In vitro study of GDNF release from biodegradable PLGA microspheres. J Control Release 2004;95:463-75.
13. Prior S, Gamazo C, Irache JM, Merkle HP, Gander B. Gentamicin encapsulation in PLA/PLGA microspheres in view of treating Brucella infections. Int J Pharm 2000;196:115-25.

14. Zolnik BS, Burgess DJ. Evaluation of in vivo-in vitro release of dexamethasone from PLGA microspheres. J Control Release 2008;127:137-45.

15. Arshady R. Preparation of biodegradable microspheres and microcapsules: Polylactides and related polyesters. J Control Release 1991;17:1-22.

16. Parikh RH, Parikh JR, Dubey RR, Soni HN, Kapadia KN. Poly (D, L-lactide-co-glycolide) microspheres containing 5-fluorouracil: Optimization of process parameters. AAPS Pharm Sci Tech 2003;4:E13.

17. Lee SC, Oh JT, Jang MH, Chung SI. Quantitative analysis of polyvinyl alcohol on the surface of poly (D, L-lactide-co-glycolide) microparticles prepared by solvent evaporation method: Effect of particle size and PVA concentration. J Control Release 1999;59:123-32.

18. Yang YY, Chung TS, Bai XL, Chan WK. Effect of preparation conditions on morphology and release profiles of biodegradable polymeric microspheres containing protein fabricated by double-emulsion method. Chem Eng Sci 2000;55:2223-36.

19. Lu L, Peter SJ, Lyman MD, Lai HL, Leite SM, Tamada JA, et al. In vitro and in vivo degradation of porous poly (DL-lactic-co-glycolic acid) foams. Biomaterials 2000;21:1837-45.

20. Park TG. Degradation of poly (lactic-co-glycolic acid) microspheres: Effect of copolymer composition. Biomaterials 1995;16:1123-30.

21. Makadia HK, Siegel SJ. Poly lactic-co-glycolic acid (PLGA) as biodegradable controlled drug delivery carrier. Polymers (Basel) 2011;3:1377-97.

How to cite this article: Madan JR, Kadam V, Bandavane S, Dua $\mathrm{K}$. Formulation and evaluation of microspheres containing ropinirole hydrochloride using biodegradable polymers. Asian J Pharm 2013;7:184-8.

Source of Support: This research work has been funded by Board of College and University Development, University of Pune.. Conflict of Interest: None declared. 
Reproduced with permission of the copyright owner. Further reproduction prohibited without permission. 